\title{
3 Research Square \\ Spatial frameworks for prioritization of agricultural research and development
}

\author{
Juan Rattalino Edreira \\ University of Nebraska-Lincoln \\ Jose Andrade \\ University of Nebraska-Lincoln \\ Kenneth Cassman \\ University of Nebraska-Lincoln https://orcid.org/0000-0002-9775-3468 \\ Martin van Ittersum \\ Wageningen University \& Research https://orcid.org/0000-0001-8611-6781 \\ Marloes van Loon \\ Wageningen University \\ Patricio Grassini ( $\nabla$ pgrassini2@unl.edu ) \\ University of Nebraska-Lincoln https://orcid.org/0000-0002-7501-842X
}

\section{Article}

Keywords: Food Security Interventions, Crop Production, Top-down Gridded Frameworks, Bottom-up Approaches

Posted Date: March 1st, 2021

DOI: https://doi.org/10.21203/rs.3.rs-267927/v1

License: (c) (i) This work is licensed under a Creative Commons Attribution 4.0 International License.

Read Full License

Version of Record: A version of this preprint was published at Nature Food on September 30th, 2021. See the published version at https://doi.org/10.1038/s43016-021-00365-y. 


\section{Abstract}

Food security interventions and policies need reliable estimates of actual crop production and the scope to enhance production on existing cropland. We assess the performance of two widely used "top-down" gridded frameworks (GAEZ and AgMIP) versus an alternative "bottom-up" approach that estimates extra production potential locally, for a number of representative sites, and then upscales the results to larger spatial scales (GYGA). Our results show that estimates from top-down frameworks are alarmingly unlikely, with estimated potential production being lower than current production at some locations. The consequences of using these coarse estimates to predict food security are illustrated by an example from sub-Saharan Africa. Our study shows that current foresights on food security, land use, and climate change and associate priority setting on AR\&D based on yield potential and yield gaps derived from topdown approaches are subject to a high degree of uncertainty and would benefit from incorporating estimates from bottom-up approaches.

\section{Main Text}

Meeting food demand on existing cropland, without further encroachment of natural ecosystems such as forests, wetlands, and savannahs, is one of the greatest challenges of our time (Cassman and Grassini, 2020). Orienting investments on agricultural research and development (AR\&D) to meet that challenge requires information about where largest opportunities to increase crop yields exist within the current cultivated area e.g., ${ }^{1,2-4}$. The yield gap, defined as the difference between actual farm yield and the yield potential with good management that minimizes yield losses from biotic and abiotic stresses, is a key biophysical indicator of the available room for crop production increase with current land and water resources ${ }^{5}$. Global assessments of future food security and land-use change published in high-profile journals have followed a top-down approach that relies on crudely-calibrated crop models and a coarse gridded spatial framework to organize data on climate, soil, and cropping systems to estimate yield potential and associated yield gaps e.g., ${ }^{6,7-9}$ (Fig. 1, Supplementary Table S1). Recent assessment for specific countries suggests, however, that top-down approaches provide estimates of yield potential and yield gaps that are not useful for effective prioritization of AR\&D investments ${ }^{10,11}$.

An alternative to the 'top-down' spatial framework is to follow a "bottom-up" approach that estimates yield potential and yield gap for a number of sites explicitly chosen to best represent the crop distribution area, and then, upscales the yield potential estimated for those sites to larger spatial scales ${ }^{12}$ (Fig. 1, Supplementary Table S1). While both spatial frameworks (i.e., top-down and bottom-up) can eventually reach full coverage of the cultivated area, they clearly differ on the means to achieve it and the resulting outcomes. Bottom-up approaches favor the use of measured data on weather, soil, and cropping systems, and the use of crop simulation models calibrated using data from well-managed experiments where yield limiting and reducing factors were effectively minimized, which, altogether, should lead to more accurate estimates of yield potential and yield gaps ${ }^{10,13}$. The spatial granularity of the bottom-up approach, in terms of estimating yield potential for a given type of climate, soil, and cropping system, 
allows results to be validated by local experts; in the case of top-down approaches, outcomes are difficult to validate because results are necessarily aggregated to grid level, without distinction by soil type and cropping system, and based on coarse weather data.

Yield potential and yield gaps are routinely used as inputs in studies dealing with global food security, biodiversity, land use, and climate changee.g., 5,14,15,16. However, despite the existence of two very different approaches to estimate these two indicators, there has been no explicit attempt to evaluate the performance of top-down versus bottom-up approaches at estimating yield potential and yield gaps at local to global scale. We report here the first global comparison of the two methods, and discuss implications at informing AR\&D investments. Our study includes outcomes from two of the most cited studies following top-down approaches: (i) the Global Agro-Ecological Zones (GAEZ) model developed by the International Institute for Applied Systems Analysis and the Food and Agricultural Organization of the United Nations http://www.fao.org/nr/gaez/en/; ${ }^{17,18}$ and (ii) the median of the model ensemble of the Agricultural Model Inter-comparison and Improvement Project AgMIP; https://agmip.org/; ${ }^{19,20}$. Yield potential, yield gaps, and extra production potential reported in these studies are compared against those derived from the bottom-up approach followed by the Global Yield Gap Atlas (GYGA; www.yieldgap.org). Because effective AR\&D requires interventions at different spatial scales, we performed the comparison between top-down and bottom-up approaches at three spatial scales: local sub-national ('climate zone'), and national or sub-continental, with a respective average size of nearly $9,500,60,000$ and $1,000,000 \mathrm{~km}^{2}$. The climate zones are geographic areas with similar temperature and water regimes ${ }^{21}$. We focus on cereal crops, which account for $45 \%$ of global calories intake (https://ourworldindata.org/food-supply). We compare top-down and bottom-up estimates for major cereal crop producing areas in North and South America, Europe, Asia, Africa, and Australia (Extended Data Fig. 1). For simplicity, we show examples on four geographic regions and three crops (maize, rice, and wheat). The four regions were selected for being important food producing and / or demanding regions. As examples of regions with favorable climate and fertile soils (i.e. favorable production environments), we include maize in the US Corn Belt, which produces $35 \%$ of global maize output, and lowland irrigated and rainfed rice in Asia, which account for about $90 \%$ of global rice production and about $80 \%$ of rice consumption $2014-2018 ;{ }^{22}$. As an example of a harsh production environment (less favorable climate and generally infertile soils), we include wheat in Australia, which accounts for $10 \%$ of global wheat exports. Maize in sub-Saharan Africa is also included as this region exhibits fast population growth rates and domestic cereal demand is projected to increase three-fold over the next 30 years ${ }^{23}$.

\section{Results}

Yield potential and yield gap comparison. Comparison of yield potential derived from top-down (GAEZ and AgMIP) versus bottom-up (GYGA) approaches reveals large discrepancies across all spatial levels. On average, yield potential estimated by AgMIP is $60 \%$ lower compared with GYGA across the four case studies (Fig. 2), which is consistent with the findings for other crop producing regions (Supplementary Table S1). As a result, AgMIP gives much more conservative estimates of extra crop production potential 
on existing cropland compared with GYGA across all spatial scales. In contrast, yield potential estimated at national and sub-continental scales by GAEZ and GYGA are fairly similar in most cases (except for rainfed US maize), with GAEZ estimates differing from GYGA by -50 to $+30 \%$. At smaller spatial scales, however, there are very large discrepancies for specific regions and crops, with GAEZ estimates differing from GYGA by -95 to $480 \%$ at local levels (Supplementary Table S1). In some cases, yield potential derived from the bottom-up and top-down approaches follows the same trend across locations and climate zones but there is still an important disagreement on the absolute level of yield potential. That was the case for maize in the US Corn Belt, where GYGA estimates a yield potential that is 8 and $63 \%$ higher than those estimated by GAEZ and AgMIP, respectively (Fig. 2A, E). Similarly, estimated yield potential for rainfed wheat in Australia is 46\% higher in GYGA than in AgMIP (Fig. 2G). Besides poor agreement at national and continental levels for some cases, there are cases in which there is a complete lack of association between the yield potential derived from top-down and bottom-up approaches across locations and climate zones, as it is the case for lowland rainfed rice in Asia and maize in sub-Saharan Africa (Fig. 2B, D, F, H). In both regions, the range of yield potential across climate zones is very narrow as estimated following top-down approaches compared with GYGA. In other words, some of the locations and climate zones reported by GYGA to have the highest yield potential are identified to be among the ones with lowest yield potential by GAEZ and AgMIP and vice versa.

Next to the (lack of) association between top-down and bottom-up approaches, we can also assess the quality of yield potential estimation by comparing the simulated yield potential against the average farm yield currently achieved (actual yields). By definition the difference between the two, the so-called yield gap (yield potential minus actual yield) cannot be negative. If an estimated yield potential value is considerably lower than average farm yield, then yield potential is clearly underestimated. In our evaluation, we found that the top-down approaches exhibited negative yield gaps for a considerable number of cases worldwide (Fig. 3, Extended Data Fig. 2). At local level, yield gaps estimated by GAEZ were negative in $13 \%, 3 \%$, and $3 \%$ of the 582,302 , and 478 locations evaluated for maize, rice, and wheat, respectively. In the case of AgMIP, yield gap estimates were negative in 39\% (maize), 45\% (rice), and 25\% (wheat) of the cases. In contrast, no negative yield gaps were estimated by GYGA. Because calculation of yield gaps relies on the same source of average actual yield data (see Methods, Section 3) for both topdown and bottom-up methods, the substantial number of cases with negative yield gaps as estimated by the top-down approaches can be seen as strong indication of underestimation of yield potential.

Implications for food self-sufficient assessments. Although achieving food self-sufficiency is not an essential precondition for food security, it can be highly relevant for developing countries with limited capacity to purchase food imports and infrastructure to store and distribute it efficiently ${ }^{24}$. A key indicator of food security is the self-sufficiency ratio (SSR), which is the ratio between domestic production and total domestic consumption e.g., ${ }^{25}$. Comparison of SSR for different scenarios of yield gap closure can help assess the degree of food self-sufficiency that a country or region can achieve by increasing productivity on existing cropland ${ }^{23}$. However, as we showed previously, such an assessment will be influenced by the choice of top-down or bottom-up approach in calculating yield potential, yield 
gaps, and associated extra production potential. For example, self-sufficiency estimates for major cereal crops (maize, sorghum, millet, rice, and wheat) vary widely across SSA countries assuming a production scenario in which average cereal crop yields reach $80 \%$ of the yield potential by year 2050 (Fig. 4). GAEZ forecasts that the region could become self-sufficient for cereal grain by year 2050 by an ample margin via narrowing current yield gaps, with the potential production exceeding expected demand by $36 \%$ (i.e., SSR=1.36). In contrast, GYGA also estimates that the region could be self-sufficient in cereals if yield gaps are closed, but with production levels very close to the expected demand by 2050 (SSR=1.03). In the case of AgMIP, estimates of crop production potential fall short of sufficiency, indicating that cropland expansion and/or increase in food imports will be needed to meet projected cereal demand by year 2050 $(\mathrm{SSR}=0.96)$. Discrepancies among approaches become larger when zooming in on specific countries or regions. For example, while GAEZ predicts that yield gap closure would result in cereal surplus in seven of the 10 countries, outputs from GYGA and AgMIP suggest that most of the countries could not meet cereal demand by year 2050. And while SSR estimates at the sub-continental scale are similar from GYGA and AgMIP, there are large differences in estimated SSR at national scale, with AgMIP estimations differing from GYGA between -24 to $39 \%$.

\section{Discussion}

A key question for AR\&D is where to invest to maximize the return on investment (ROI). While yield gap alone is not sufficient to answer this question, together with other biophysical and socio-economic factors that influence technology adoption, it is an important parameter to guide public and private investments in agriculture since it specifies where and how much crop production can be increased. Here we showed that the choice of top-down or bottom-up approach has important implications for projecting ROI. For example, different approaches lead to contrasting answers about the prognosis of a given country to reach a desired level of food self-sufficiency. And even in those cases in which both approaches give similar yield gap estimates at sub-continental level, there are large discrepancies when looking at specific countries or regions within each country. The considerable number of locations with negative yield gap estimated by top-down approaches raises important questions about the accuracy of these approaches in estimating yield potential, and urges caution about their use as it would result in less effective prioritization of R\&D investments in agriculture and reduced ROI. And while we focused on extra production potential and food availability, the uncertainty associated with top-down analysis will also apply to other studies focusing on land use, climate change, and biodiversity that follow a similar approach to estimate crop production potential.

Causes for inaccurate estimation of yield gaps following top-down approaches have been investigated elsewhere e.g., 26,27 ; here we point out some of them. The two top-down approaches included in this study rely on coarse gridded weather data and global soil maps (Supplementary Table S1). Previous studies have shown important biases when simulating yield potential using coarse gridded weather data compared with simulations based on measured data e.g., ${ }^{27,28,29}$ or without proper selection of the dominant soil types within an agricultural area e.g., ${ }^{30,31}$. Similarly, the cropping-system context, in 
relation to crop intensity (i.e., number of crops per year), crop calendar (sowing window and crop cycle duration), and water regime (irrigated or rainfed) is critical for the estimation of yield potential. While GYGA works with local experts to obtain reliable information about the cropping system context, the two top-down approaches rely on an in silico optimization of the cropping system (GAEZ) or coarse global crop calendars (AgMIP), predicting in many cases crop systems that do not match the existing ones or simply do not exist. For example, in the US Corn Belt, the global dataset MIRCA $2000^{32}$ employed by AgMIP sets a maize sowing window between April and October but, in reality, producers typically do not sow beyond June to prevent crop loss due to fall frost ${ }^{33}$. Likewise, top-down approaches generally use generic crop model coefficients that do not account for the specificity of crop cultivars, in terms of responses to temperature and photoperiod $20,34,35$; these models are also rarely validated for their ability to estimate yield potential based on data collected from well managed crops where yield-limiting and yield-reducing factors have been effectively controlled. To summarize, estimates of yield potential and yield gaps delivered via top-down approaches are subjected to a high degree of uncertainty considering the errors associated with the underpinning data.

The accuracy of the spatial sampling framework of the GYGA bottom-up approach has been validated for regions where high-quality and spatially detailed data are available. Hochman, et al. ${ }^{36}$ conducted a study on yield gaps of rainfed wheat in Australia following two approaches: (i) the bottom-up approach of GYGA and (ii) a data rich method using high density data available in the Australian grain zone (both relying on measured weather data). These researchers reported that the two approaches gave similar estimates of yield potential and yield gaps at climate zone and national levels. Similarly, Aramburu Merlos, et al. ${ }^{37}$ and Morell, et al. ${ }^{38}$ show that national average actual yield estimates for Argentina and USA, calculated using a limited number of selected locations following the GYGA protocols, were remarkably similar to the reported national average yield based on data from hundreds of subnationallevel administrative units covering the entire crop production area. Finally, Van Wart et al. (2013b) and van Bussel et al. (2015) showed that variability in weather and simulated yield potential was relatively low for sites located within the same climate zones, which provides further support for a stratified (instead of random) selection of sites and use of the climate zone framework as basis for upscaling results from location to region and country. Altogether, these studies provide evidence of the robust estimates of yield potential and yield gaps following the bottom-up approach of the Global Yield Gap Atlas.

Although estimating yield gaps following a bottom-up instead of a top-down approach requires more time and efforts, we argue from our experience at developing GYGA that a conscious effort to estimate yield gap for all major cropping systems in the world following a robust bottom-up approach, and to keep the platform updated over time, can be accomplished in a relatively short timeframe and with a modest investment. Another apparent trade-off of the bottom-up approach is related with its large data requirement, which would make, in principle, its application difficult in regions where these data are scarce or simply do not exist. Nevertheless, a bottom-up approach that is flexible to accommodate different scenarios of data availability and quality, giving priority to best sources of data when these 
exist, can help identify 'data gaps' that should be filled in the future. Along these lines, GYGA follows a tier preference approach ${ }^{31}$ that gives priority to the use of measured weather data and fine-scale soil maps, but allows the use of gridded weather data or global soil databases as a last resort for sites in which measured data do not exist, making these decisions in an explicit way so that these data gaps can eventually be filled with better data. In contrast, top-down approaches based on unmeasured gridded data or coarse global soil maps give a false sense of availability of quality data at fine spatial resolution, since their estimates are provided for the entire planet (or the entire cropland area) in spatial grids that are typically $0.5-2.0^{\circ}$ (ca. 3,000 to $50,000 \mathrm{~km}^{2}$ at the equator). Regardless of the means to do it, one thing is clear: current foresights on food security, land use, and climate change and associate priority setting on AR\&D based on yield potential and yield gaps derived from top-down approaches is subject to a high degree of uncertainty and would benefit from incorporating estimates from bottom-up approaches to their decision making.

\section{Declarations}

\section{Acknowledgements}

This study was supported by the Bill and Melinda Gates Foundation, Wageningen University \& Research, and the CGIAR research program on Climate Change, Agriculture, and Food Security (CCAFS).

\section{Author Contributions}

Research was conceived by JIRE, PG, KC, and Mvl. Data acquisition, data processing, and statistical analysis were performed by JIRE, JFA, and MvL. The manuscript was written by JIRE and PG with input from all authors.

\section{Competing interest declaration}

The authors declare no competing interests.

\section{References}

1 Pardey, P. G., Chan-Kang, C., Dehmer, S. P. \& Beddow, J. M. Agricultural R\&D is on the move. Nature Comment 537, 301-303 (2016).

2 Wood, S. \& Pardey, P. G. Agroecological aspects of evaluating agricultural R\&D. Agric. Sys. 57, 13-41 (1998).

3 Alston, J. M., Norton, G. W. \& Pardey, P. G. Science under scarcity: principles and practice for agricultural research evaluation and priority setting. 618 (Cornell University Press, 1995).

4 Folberth, C. et al. The global cropland-sparing potential of high-yield farming. Nature Sustainability 3, 281-289, doi:10.1038/s41893-020-0505-x (2020). 
5 Godfray, H. C. J. et al. Food security: The challenge of feeding 9 billion people. Science 327, 812-818, doi:10.1126/science.1185383 (2010).

6 Springmann, M. et al. Options for keeping the food system within environmental limits. Nature 562, 519-525, doi:10.1038/s41586-018-0594-0 (2018).

7 Erb, K.-H. et al. Exploring the biophysical option space for feeding the world without deforestation. Nature Communications 7, 11382, doi:10.1038/ncomms11382 (2016).

8 Koh, L. P. \& Ghazoul, J. Spatially explicit scenario analysis for reconciling agricultural expansion, forest protection, and carbon conservation in Indonesia. Proceedings of the National Academy of Sciences 107, 11140, doi:10.1073/pnas.1000530107 (2010).

9 van Vliet, J. Direct and indirect loss of natural area from urban expansion. Nature Sustainability 2, 755763, doi:10.1038/s41893-019-0340-0 (2019).

10 van Ittersum, M. K. et al. Yield gap analysis with local to global relevance-A review. Field Crops Res., doi:http://dx.doi.org/10.1016/j.fcr.2012.09.009 (2012).

11 Deng, N. et al. Closing yield gaps for rice self-sufficiency in China. Nature Communications 10, doi:10.1038/s41467-019-09447-9 (2019).

12 van Bussel, L. G. J. et al. From field to atlas: Upscaling of location-specific yield gap estimates. Field Crops Res. 177, 98-108 (2015).

13 Grassini, P. et al. Robust spatial frameworks for leveraging research on sustainable crop intensification. Global Food Security 14, 18-22, doi:https://doi.org/10.1016/j.gfs.2017.01.002 (2017).

14 Foley, J. A. et al. Solutions for a cultivated planet. Nature 478, 337, doi:10.1038/nature10452 (2011).

15 Bruinsma, J. The resource outlook to 2050: by how much do land, water and crop yields need to increase by 2050?, (FAO, 2009).

16 Suh, S. et al. Closing yield gap is crucial to avoid potential surge in global carbon emissions. Glob. Environ. Change 63, 102100, doi:https://doi.org/10.1016/j.gloenvcha.2020.102100 (2020).

17 Fischer, G., Shah, M., van Velthuizen, H. \& Nachtergaele, F. O. Global agro-ecological assessment for agriculture in the 21st century. (IIASA, 2001).

18 IIASA/FAO. Global agro-ecological zones (GAEZ v3.0). IIASA, Laxenburg, Austria and FAO, Rome, Italy. (2012).

19 Rosenzweig, C. et al. The Agricultural Model Intercomparison and Improvement Project (AgMIP): Protocols and pilot studies. Agric. For. Meteorol. 170, 166-182, doi:https://doi.org/10.1016/j.agrformet.2012.09.011 (2013). 
20 Elliott, J. et al. The global gridded crop model intercomparison: data and modeling protocols for Phase 1 (v1.0). Geosci. Model Dev. 8, 261-277, doi:10.5194/gmd-8-261-2015 (2015).

21 van Wart, J. et al. Use of agro-climatic zones to upscale simulated crop yield potential. Field Crops Res. 143, 44-55 (2013).

22 FAOSTAT. Crops and livestock trade database www.faostat.fao.org, 2021).

23 van Ittersum, M. K. et al. Can sub-Saharan Africa feed itself? Proceedings of the National Academy of Sciences 113, 14964-14969, doi:10.1073/pnas.1610359113 (2016).

24 Clapp, J. Food self-sufficiency: Making sense of it, and when it makes sense. Food Policy 66, 88-96, doi:https://doi.org/10.1016/j.foodpol.2016.12.001 (2017).

25 Alexandratos, N. \& Bruinsma, J. World agriculture towards 2030/2050: the 2012 revision. (Agricultural Development Economics Division. Food and Agriculture Organization of the United Nations 2012).

26 Blankenau, P. A., Kilic, A. \& Allen, R. An evaluation of gridded weather data sets for the purpose of estimating reference evapotranspiration in the United States. Agric. Water Manag. 242, 106376, doi:https://doi.org/10.1016/j.agwat.2020.106376 (2020).

27 Mourtzinis, S., Rattalino Edreira, J. I., Conley, S. P. \& Grassini, P. From grid to field: Assessing quality of gridded weather data for agricultural applications. Eur. J. Agron. 82, Part A, 163-172, doi:http://dx.doi.org/10.1016/j.eja.2016.10.013 (2017).

28 van Wart, J., Grassini, P. \& Cassman, K. G. Impact of derived global weather data on simulated crop yields. Global Change Biology 19, 3822-3834 (2013).

29 Ramirez-Villegas, J. \& Challinor, A. Assessing relevant climate data for agricultural applications. Agric. For. Meteorol. 161, 26-45, doi:https://doi.org/10.1016/j.agrformet.2012.03.015 (2012).

30 Hendriks, C. M. J., Stoorvogel, J. J. \& Claessens, L. Exploring the challenges with soil data in regional land use analysis. Agric. Sys. 144, 9-21, doi:10.1016/j.agsy.2016.01.007 (2016).

31 Grassini, P. et al. How good is good enough? Data requirements for reliable crop yield simulations and yield-gap analysis. Field Crops Res., 49-63 (2015).

32 Portmann, F. T., Siebert, S. \& Döll, P. MIRCA2000-Global monthly irrigated and rainfed crop areas around the year 2000: A new high-resolution data set for agricultural and hydrological modeling. Glob. Biogeochem. Cycles 24, doi:10.1029/2008gb003435 (2010).

33 Grassini, P., Specht, J. E., Tollenaar, M., Ciampitti, I. A. \& Cassman, K. G. in Crop physiology. Applications for genetic improvement and agronomy (eds Víctor O. Sadras \& Daniel F. Calderini) 15-42 (Oxford: Academic Press, 2015). 
34 Müller, C. et al. The Global Gridded Crop Model Intercomparison phase 1 simulation dataset. Scientific Data 6, 50, doi:10.1038/s41597-019-0023-8 (2019).

35 Robinson, S. et al. The International Model for Policy Analysis of Agricultural Commodities and Trade (IMPACT): Model description for version 3. (2015).

36 Hochman, Z., Gobbett, D., Horan, H. \& Navarro Garcia, J. Data rich yield gap analysis of wheat in Australia. Field Crops Res. 197, 97-106, doi:http://dx.doi.org/10.1016/j.fcr.2016.08.017 (2016).

37 Aramburu Merlos, F. et al. Potential for crop production increase in Argentina through closure of existing yield gaps. Field Crops Res. 184, 145-154 (2015).

38 Morell, F. J. et al. Can crop simulation models be used to predict local to regional maize yields and total production in the U.S. Corn Belt? (2016).

39 Evans, L. T. Crop Evolution, adaptation, and yield., (Cambridge University Press, 1993).

40 Cassman, K. G. Ecological intensification of cereal production systems: Yield potential, soil quality, and precision agriculture. Proc. Natl. Acad. Sci. U. S. A. 96, 5952-5959 (1999).

41 Lobell, D. B., Cassman, K. G. \& Field, C. B. in Annual Review of Environment and Resources Vol. 34 179-204 (2009).

42 van Wart, J., Kersebaum, K. C., Peng, S., Milner, M. \& Cassman, K. G. Estimating crop yield potential at regional to national scales. Field Crops Res. in press, doi:http://dx.doi.org/10.1016/j.fcr.2012.11.018 (2013).

43 You, L. et al. (2014).

44 International Food Policy Research Institute. (2019).

45 United Nations. World Population Prospects, the 2015 Revision. (United Nations, New York, 2015). 46 FAO. Food balance sheets. A handbook. (FAO, Rome, 2001).

47 O'Neill, B. C. et al. A new scenario framework for climate change research: the concept of shared socioeconomic pathways. Clim. Change 122, 387-400, doi:10.1007/s10584-013-0905-2 (2014).

\section{Methods}

1. Yield definitions 
Yield potential is defined as the yield of a cultivar in an environment to which it is adapted, when grown with sufficient water and nutrients in the absence of abiotic and biotic stress ${ }^{39}$. In irrigated fields, yield potential $(\mathrm{Yp})$ is determined by solar radiation, temperature, atmospheric $\mathrm{CO}_{2}$ concentration, and management practices that influence crop cycle duration and light interception, such as sowing date, cultivar maturity, and plant density. In rainfed systems where water supply from stored soil water at sowing and in-season precipitation is not enough to meet crop water requirement, water-limited yield potential $(\mathrm{Yw})$ is determined by water supply amount and its distribution during the growing season, and by soil properties influencing the crop water balance, such as the rootable soil depth, texture, and terrain slope. Actual yield is defined as the average grain yield ( $t$ per harvested ha) obtained by farmers for a given crop with a given water regime. The difference between $Y p$ (or $Y w$ ) and farmer actual yield is known as the yield gap ${ }^{10}$. In the case of irrigated crops, Yp is the proper benchmark to estimate yield gaps while $Y w$ is the meaningful benchmark for rainfed crops. With good, cost-effective crop management, reaching $70-80 \%$ of $Y p$ (or $Y w$ ) is a reasonable target for farmers with good access to markets, inputs, and extension services ${ }^{40,41}$. Beyond this yield level, the small return to extra input requirement and labor does not justify the associated costs and level of sophistication in crop and soil management practices.

\section{Sources of yield potential data derived from top-down and bottom-up approaches}

We retrieved data generated from two initiatives following a top-down approach: (i) the Global AgroEcological Zones (GAEZ) http://www.fao.org/nr/gaez/en/; ${ }^{17,18}$ and (ii) the Agricultural Model Intercomparison and Improvement Project (AgMIP) https://agmip.org/; ${ }^{19,20}$. As an example of a bottomup approach, we used results from the Global Yield Gap Atlas GYGA; www.yieldgap.org; ${ }^{10,31,42}$. Main features of these databases are summarized in Table 1. In the process of selecting the specific dataset, we explicitly attempted to reduce biases in the comparisons to the extent this was possible. For example, in all cases, we used simulations that meet the yield definitions provided in the previous section. We also try to be consistent in terms of the time period for which Yp (or Yw) was simulated; however, this was not always possible because while GAEZ and AgMIP use weather data sets that cover the time period between 1961-1990 and 1980-2010, respectively, GYGA uses more recent weather data (Table 1). Similarly, comparison between databases where limited to those regions for which there were estimates of $Y p$ (or $Y w$ ) for the each of the top-down and bottom-up approaches. More detailed information about the three approaches can be seen in Section 1 of the Supplementary Materials.

Table 1. Summary of most relevant features of the databases used in this study to compare top-down versus bottom-up approaches. 


\begin{tabular}{|c|c|c|c|}
\hline Features & $\begin{array}{l}\text { Global Agro-Ecological Zones } \\
\text { (GAEZ) }\end{array}$ & $\begin{array}{l}\text { Agricultural Model } \\
\text { Intercomparison and } \\
\text { Improvement Project } \\
\text { (AgMIP) }\end{array}$ & $\begin{array}{l}\text { Global Yield Gap Atlas } \\
\text { (GYGA) }\end{array}$ \\
\hline Approach & Top-down & Top-down & Bottom-up \\
\hline $\begin{array}{l}\text { Crop } \\
\text { model }\end{array}$ & $\begin{array}{l}\text { Single, generic model based on } \\
\text { monthly weather data that uses } \\
\text { generic crop parameters to } \\
\text { simulate different crops } \\
\text { (Kassam, 1977). The model is } \\
\text { not locally calibrated. }\end{array}$ & $\begin{array}{l}\text { Combination of (i) } \\
\text { generic and crop- } \\
\text { specific, (ii) site-based } \\
\text { process and } \\
\text { ecosystem, and (iii) } \\
\text { calibrated and non- } \\
\text { calibrated models } \\
\text { (Table S2). }\end{array}$ & $\begin{array}{l}\text { Crop-specific model, } \\
\text { simulates crop growth on } \\
\text { a daily step. To the extent } \\
\text { it is possible, models are } \\
\text { calibrated for each study } \\
\text { region. }\end{array}$ \\
\hline \multicolumn{4}{|l|}{$\begin{array}{l}\text { Data } \\
\text { source }\end{array}$} \\
\hline Weather & $\begin{array}{l}\text { Gridded weather (Climate } \\
\text { Research Unit and GPCC) }\end{array}$ & $\begin{array}{l}\text { Gridded weather data } \\
\text { (including, but not } \\
\text { limited, to AgMERRA, } \\
\text { WFDEl, and GPCC) }\end{array}$ & $\begin{array}{l}\text { Tier selection approach: } \\
\text { weather station data ( } 1^{\text {st }} \\
\text { option), corrected } \\
\text { measured data ( } 2^{\text {nd }} \\
\text { option) \& NASA gridded } \\
\text { data ( } 3^{\text {rd }} \text { option). }\end{array}$ \\
\hline Soil & $\begin{array}{l}\text { Global gridded soil database } \\
\text { (Harmonized World Soil } \\
\text { Database, FAO/IIASA/ISRIC, } \\
\text { 2009). }\end{array}$ & $\begin{array}{l}\text { Different models use } \\
\text { different soil } \\
\text { databases and, in } \\
\text { some cases, soil was } \\
\text { ignored or not } \\
\text { documented }\end{array}$ & $\begin{array}{l}\text { Tier selection approach: } \\
\text { high-quality national soil } \\
\text { maps ( } 1^{\text {st }} \text { option), global } \\
\text { soil databases ( } 2^{\text {nd }} \\
\text { option) \& expert opinion } \\
\text { ( } 3^{\text {rd }} \text { option). }\end{array}$ \\
\hline $\begin{array}{l}\text { Cropping } \\
\text { system }\end{array}$ & $\begin{array}{l}\text { Crop cycle length is determined } \\
\text { in silico by optimizing crop cycle } \\
\text { with the length of growing } \\
\text { season. Cropping system is } \\
\text { incorrect or oversimplified in } \\
\text { many cases. }\end{array}$ & $\begin{array}{l}\text { Coarse global crop } \\
\text { calendars, e.g., } \\
\text { MIRCA2000 } \\
\text { (Portmann et al., } \\
\text { 2010) and SAGE } \\
\text { (Sacks et al., 2010). } \\
\text { Cropping system is } \\
\text { incorrect of } \\
\text { oversimplified in } \\
\text { many cases. }\end{array}$ & $\begin{array}{l}\text { Cropping system data } \\
\text { provided by local experts, } \\
\text { including crop sequence, } \\
\text { sowing date, crop cycle } \\
\text { duration, and water } \\
\text { regime. }\end{array}$ \\
\hline $\begin{array}{l}\text { Time } \\
\text { period }\end{array}$ & 30 years (1961-1990) & 31 years $(1980-2010)$ & $\begin{array}{l}\text { Minimum of } 10 \\
\text { (irrigated) and } 20 \text { years } \\
\text { (rainfed), using the most } \\
\text { updated data that is } \\
\text { available after } 1980 .\end{array}$ \\
\hline $\begin{array}{l}\text { Finest } \\
\text { level of } \\
\text { spatial } \\
\text { resolution }\end{array}$ & $\begin{array}{l}\text { Grids of } c a .100 \mathrm{~km}^{2} \text { near the } \\
\text { equator }\end{array}$ & $\begin{array}{l}\text { Grids of ca. } 3,000 \\
\mathrm{~km}^{2} \text { at equator }\end{array}$ & $\begin{array}{l}\text { Buffers around weather } \\
\text { stations, with border } \\
\text { clipped by climate zones, } \\
\text { and size varying from } \\
200 \text { to } 31,000 \mathrm{~km}^{2} \text {. }\end{array}$ \\
\hline Upscaling & No upscaling is needed as yield & No upscaling is & Uses a climate zone \\
\hline
\end{tabular}


needed as yield potential is simulated for each grid scheme for upscaling yield from buffer to climate zone, and then from climate zone to country or continental levels.

http://www.yieldgap.org/;

https://agmip.org/;

Elliot et al., 2015;

Muller et al., 2017, 2019
Grassini et al., 2015; van

Bussel et al., 2015.
Fischer et al., 2002, IIASA/FAO, 2012

\section{Comparison of bottom-up and top-down approaches at different spatial levels}

Comparison of the three databases needs to account for the different spatial resolution at which the data are reported (grid in GAEZ and AgMIP versus buffer in GYGA). In the present study, we compared Yp (or $\mathrm{Yw}$ ) among the three databases at three spatial levels: local (also referred as "buffer"), climate zone, and country. An example of the three spatial levels evaluated in this study as well as the Yw estimated by each of the three databases for rainfed maize is shown in Extended Data Fig. 3. We note that buffer is the lowest spatial level at which Yp and Yw are reported in GYGA. For a country such as USA, where maize production is concentrated on flat geographic areas, average size of buffers and climate zones selected by GYGA is 17,000 and $60,000 \mathrm{~km}^{2}$, respectively; the size is smaller for countries with greater terrain and climate heterogeneity, such as it is the case of Ethiopia, where average size of buffers and climate zone selected for maize by GYGA is a respective 4,000 and $21,000 \mathrm{~km}^{2}$, or for smaller countries, such as in Europe.

The GYGA already provides estimates of Yp (or Yw) and yield gaps at those three spatial levels. Following a bottom-up approach, GYGA estimates the Yp (or Yw) at buffer level based on the Yp (or Yw) simulated for each crop cycle and soil type (within a given buffer) and their associated harvested area (within that same buffer) using a weighted average. Subsequently, Yp (or Yw) at buffer levels are upscaled to CZ, national, or (sub-)continental levels using a weighted average based on harvested area retrieved from SPAM 2010 (You et al., 2014). Details on the GYGA upscaling method can be found in van Bussel, et al. ${ }^{12}$. In the case of top-down approaches, for comparison purposes, it was necessary to aggregate $Y p$ (or $Y w$ ) reported for each individual grid into buffers, climate zones, and countries in order to make them comparable to those reported by GYGA. To do so, Yp (or Yw) from GAEZ and AgMIP were scaled up to buffer, climate zone, and country (or-subnational levels) considering the crop-specific area within each pixel, as reported by the Spatial Production Allocation Model SPAM 2010; ${ }^{43}$. For example, for a given buffer, the average $Y p$ (or $Y w$ ) was estimated using a weighted average, in which the value of $Y p$ (or Yw) reported for each of the GAEZ or AgMIP grids located within the GYGA buffer was 'weighted' according to the SPAM crop specific area within that grid. Same approach was used to estimate average Yp (or Yw) at climate zone and country (or sub-continental) levels for GAEZ and AgMIP. 
For a given buffer, climate zone, or country (or sub-continent), the yield gap was calculated as the difference between $Y p$ (or $Y w$ ) and the average farmer yield (actual yield, Ya). The Yp and Yw were taken as the appropriate benchmarks to estimate yield gaps for irrigated and rainfed crops, respectively. To avoid biases due to the source of average yield in the estimation of yield gap, we used the average yield dataset from GYGA because it provides estimates of average yield disaggregated by water regime and for the most recent time period. Actual yield data were retrieved from official statistics available at subnational administrative units such as municipalities, counties, departments, and sub-district. The exact number of years of data to calculate average yield is determined by GYGA on a case-by-case basis, following the principle of including as many recent years of data as possible to account for weather variability whole avoiding the bias due to a technological time-trend and long-term climate change ${ }^{31}$. Using GYGA database on average yield for estimation of yield gaps will not biased the results from our study as GYGA favors the use of official sources of average yields at the finer available spatial resolution, which is the same source of actual yield data used by other databases such as FAO and SPAM ${ }^{22,44}$. In this study, we opted not to use actual yield data from GAEZ because they derived from FAOSTAT statistics of the years 2000 and 2005, and thus, they could lead to an overestimation of the yield gap in those regions where actual yields have increased over the past two decades ${ }^{18}$. Finally, extra production potential was calculated based on the yield gap estimated by each approach and the SPAM crop-specific harvested area reported for each buffer, climate zone, and country (or sub-continent). The top-down and bottom-up approaches were compared in a total of 67 countries, which together account for $74 \%, 67 \%$, and $43 \%$ of global maize, rice, and wheat harvested areas, respectively (Extended Data Fig. 1). Overall, our comparison included a total of 1362 buffers located within 870 climate zones, with 422 buffers (within $249 \mathrm{CZs}$ ) for rainfed maize, 160 buffers $(116 \mathrm{CZs})$ for irrigated maize, 93 buffers $(66 \mathrm{CZs})$ for rainfed rice, 209 buffers ( $114 \mathrm{CZs}$ ) for irrigated rice, 400 buffers ( $274 \mathrm{CZs}$ ) for rainfed wheat, and 78 buffers ( $49 \mathrm{CZs}$ ) for irrigated wheat. In all cases, Yp (or Yw), yield gaps, and extra production potential were expressed at standard commercial moisture content that is $15.5 \%$ for maize, $14 \%$ for rice, and $13.5 \%$ for wheat.

We assessed the agreement in Yp (or Yw), yield gap, and extra production potential between GYGA and the two databases that follow a top-down approach (GAEZ and AgMIP) separately for each of the spatial levels (buffer, climate zone, country or subcontinent) by calculating root mean square error (RMSE) and absolute mean error (ME):

$$
\begin{aligned}
& \text { RMSE }=\sqrt{\frac{\sum\left(Y_{T D}-Y_{B U}\right)^{2}}{n}} \\
& M E=\frac{\sum\left(Y_{T D}-Y_{B U}\right)}{n}
\end{aligned}
$$

where $Y_{i}$ and $Y_{G Y G A}$ are the estimated $Y p$ (or $Y w$ ), yield gap, or extra production potential for database $i$ following a top-down approach and for GYGA, respectively, and $n$ is the number of paired $Y_{i}$ versus $Y_{B U}$ 
comparisons at a given spatial scale for a given crop in a given country. Separate comparisons were performed for irrigated and rainfed crops.

\section{Impact of yield potential estimates on food security analysis}

We assessed the impact of discrepancies in Yp (or Yw) between top-down and bottom-up approached on the self-sufficiency ratio (SSR), which is an important indicator for food security. To do so, we focused on cereal crops in sub-Saharan Africa and we calculated the SSR for the five main cereal crops in SubSaharan Africa (i.e., maize, millet, rice, sorghum, and wheat) following van Ittersum et al. (2016). Millet and sorghum were included in the analysis of SSR in sub-Saharan Africa because together they account for $c a .15 \%$ of the total cereal production and ca. $25 \%$ of the total cereal harvested area in this region. Briefly, we computed current national demand (assumed equal to the 2015 consumption) and the 2015 production of the five cereals to estimate the baseline SSR (i.e., in year 2015) in ten countries for which Yw data were available in GYGA. Current total cereal demands per country were calculated as the product of current population size derived from UN population prospects and cereal demand per capita based on IMPACT ${ }^{35,45}$. The annual per capita demand for the five cereals was expressed in maize yield equivalents by using the crop-specific grain caloric contents, with caloric contents based on FAO food balances ${ }^{46}$. Current domestic grain production per cereal crop per country (approximately year 2015) was calculated as mean actual crop yield (2003-2012) as estimated in GYGA times the 2015 harvested area per crop by $F A O^{22}$. Total future annual cereal demand per capita (2050), for each of the five cereals and each country, was retrieved from IMPACT modeling results ${ }^{35}$, using The Shared Socioeconomic Pathway (SSP2, no climate change) from the Intergovernmental Panel on Climate Change (IPCC) fifth assessment ${ }^{47}$. Total cereal demand per country in year 2050 was calculated based on projected 2050 population (medium fertility variant of UN population prospects, https://population.un.org/wpp/) multiplied by the per capita cereal demand in 2050 from the SSP2 scenario. In our study, we assumed an attainable yield of $80 \%$ of $Y p$ (or Yw in the case of rainfed crops) instead of $85 \%$ as in the original approach followed by van Ittersum et al. (2016) to be slightly more conservative. Because the goal was to understand the level of SSR on existing cropland, we assumed no expansion of rainfed or irrigated cropland and no change in net planted area for each of the cereal crops.

\section{Data availability}

Data on yield potential and actual yield from GYGA are available at www.yieldgap.org. Data on yield potential from AgMIP and GAEZ can be download from www.fao.org/nr/gaez/en and www.agmip.org, respectively.

\section{Figures}


1. Identification of grids with crop area (some approaches do not identify cropland)

2. Retrieval of weather, soil, and cropping system data from coarse, global databases

3. Simulation of yield potential for each grid based on generic model parameters

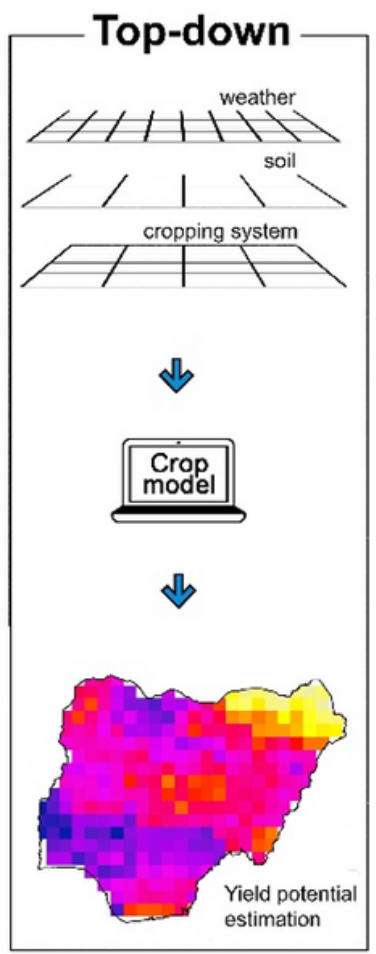

Bottom-up

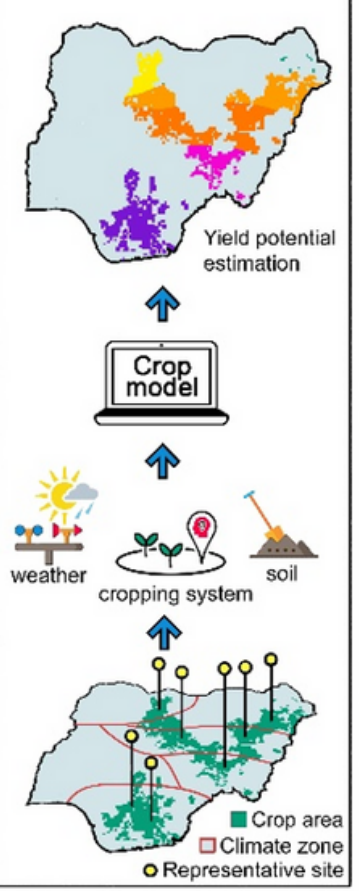

3.Simulation of yield potential for each site using validated models and upscaling yield potential to climate zone (shown in map) and country levels

2. Retrieval of best available observed data on weather, soil, and cropping system assisted by local experts

1. Identification of climate zones with crop area and strategic selection of 'representative' sites

\section{Figure 1}

Main differences between top-down and bottom-up approaches at estimating crop yield potential. Schematic representation of the steps followed by top-down (left) and bottom-up (right) approaches to estimate yield potential in one country.

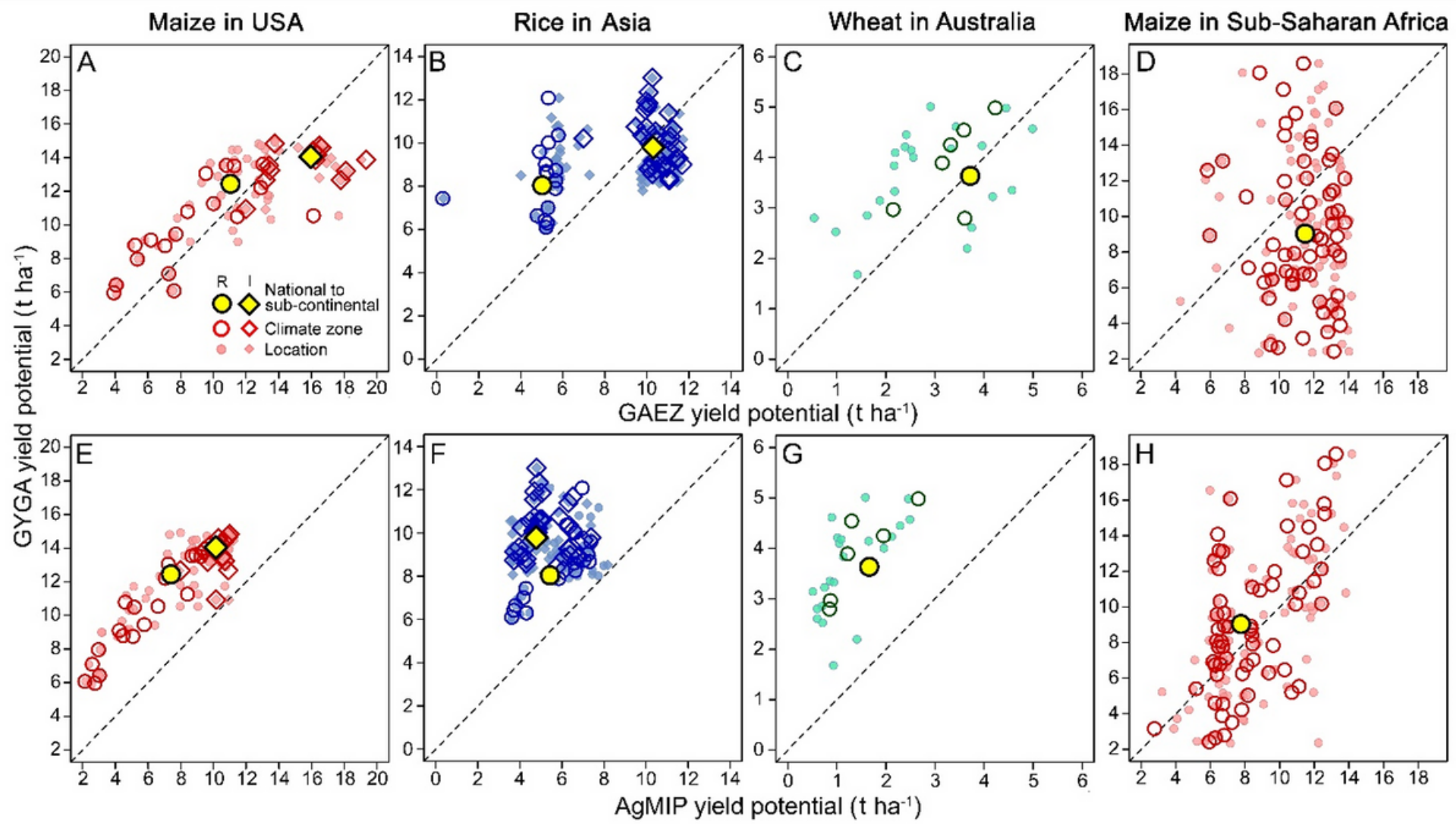


Figure 2

Comparison of yield potential derived from top-down and bottom-up approaches. Yield potential derived from the bottom-up Global Yield Gap Atlas (GYGA) versus those estimated following the top-down GAEZ (upper panels) or AgMIP (bottom panels) for rainfed (R) and irrigated (I) maize, rice, and wheat in four crop producing regions and at three spatial scales: local, regional (climate zone), and national or subcontinental. Each data point represents a long-term average yield potential (10-30 years of data, depending on case study). Dashed line indicates $x=y$. Comparisons for other cropping systems are shown in the Supplementary Table S1.
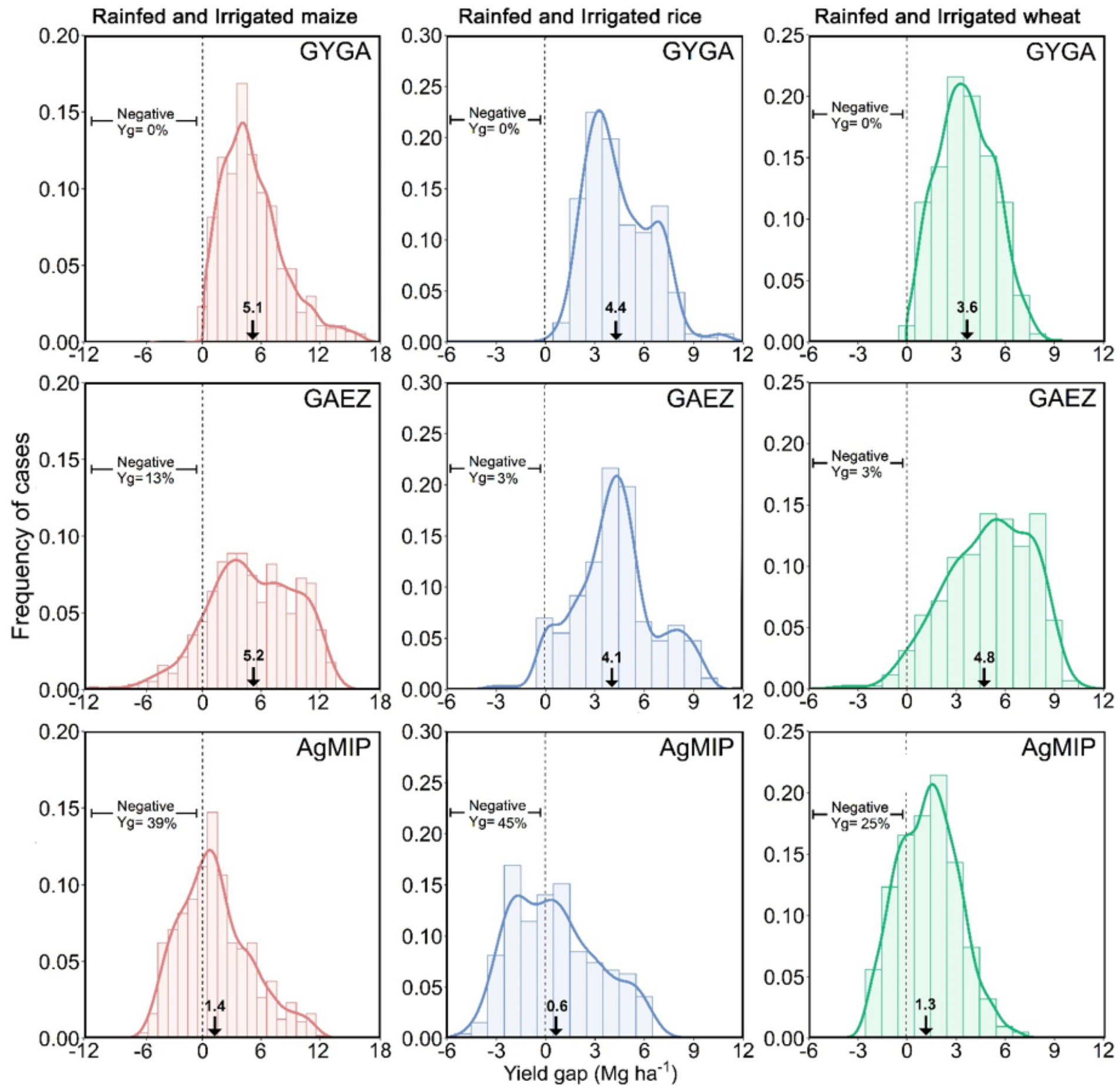


\section{Figure 3}

Yield gaps as estimated using bottom-up and top-down approaches. Histogram of yield gap (Yg) estimation for rainfed and irrigated maize, rice, and wheat at local scale using the Global Yield Gap Atlas (GYGA), the Global Agro-Ecological Zones (GAEZ), and the Agricultural Model Intercomparison and Improvement Project (AgMIP) frameworks. Arrows indicate the mean yield gap estimated across 582 locations for maize, 302 for rice, and 478 for wheat.

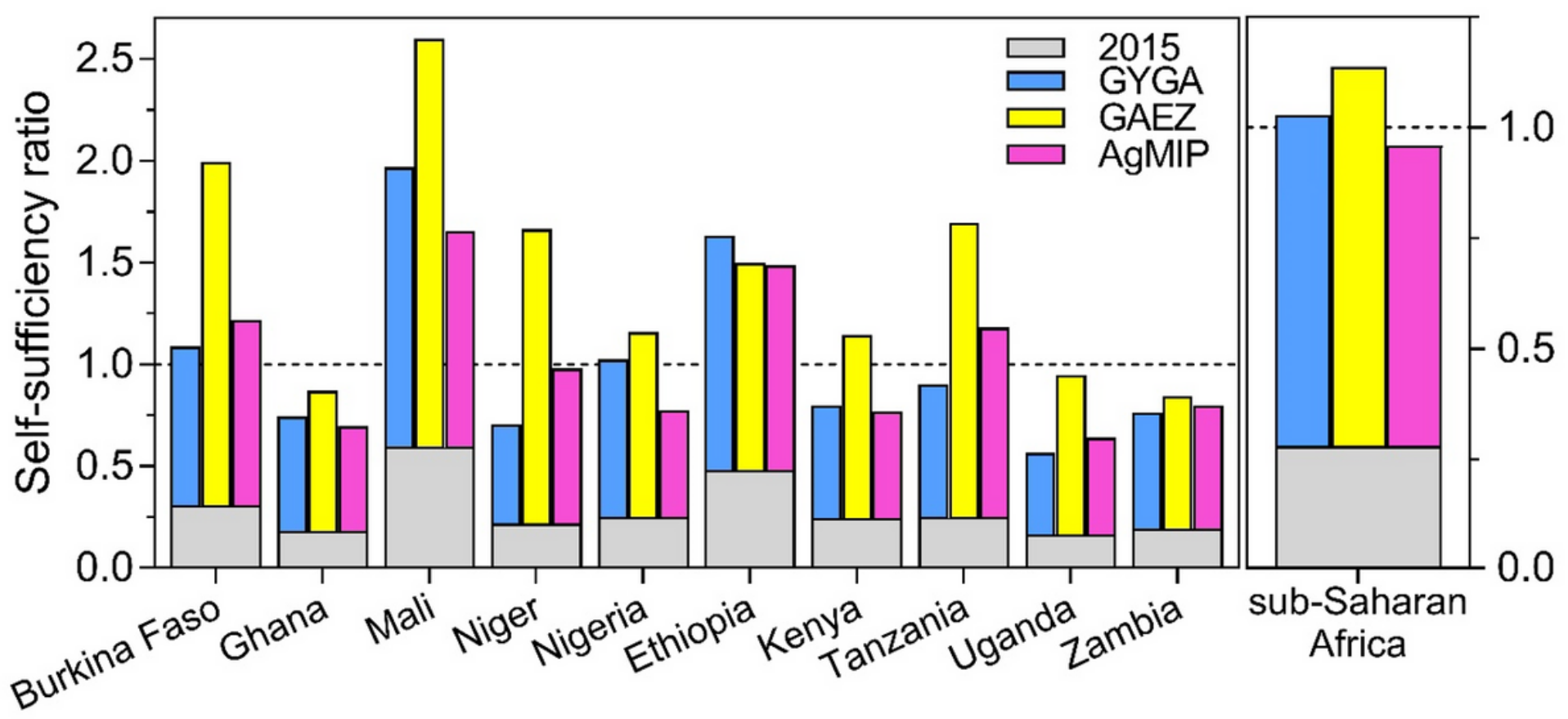

\section{Figure 4}

Cereal self-sufficiency for a scenario of yield gap closure in sub-Saharan Africa by year 2050 as estimated using bottom-up and top-down approaches. Self-sufficiency ratio (SSR) was calculated as the quotient between production and demand of most important cereals. The gray portion of the bars represents the SSR by 2050 assuming production level as for 2015; the colored portion represents the SSR if farmers close the exploitable yield gap (i.e., reach $80 \%$ of the yield potential). Separate bars are shown for bottom up (GYGA) and top-down approaches (GAEZ and AgMIP).

\section{Supplementary Files}

This is a list of supplementary files associated with this preprint. Click to download.

- RattalinoEdreiraetalSupplementaryMaterial.docx

- ExtendedData.docx 